\title{
ATTRIBUTION AND CHARACTERISATION OF SCLEROPHYLL FORESTED LANDSCAPES OVER LARGE AREAS
}

\author{
Simon Jones ${ }^{\text {ac*}}$, Mariela Soto-Berelov ${ }^{\text {ac }}$, Lola Suarez ${ }^{\text {ac }}$, Phil Wilkes ${ }^{\text {ac }}$, Will Woodgate ${ }^{\text {ac }}$, Andrew Haywood ${ }^{\text {bcd }}$ \\ ${ }^{a}$ Centre for Remote Sensing, School of Mathematical and Geospatial Sciences, RMIT University, Melbourne, Australia \\ (simon.jones, mariela.sotoberelov, lola.suarez, phil.wilkes)@rmit.edu.au \\ ${ }^{\mathrm{b}}$ Department of Environment, Land Water and Planning, East Melbourne, 3002, Victoria, Australia \\ ${ }^{\mathrm{c}}$ Coopertive Research Centre for Spatial Information, Carlton, 3053, Victoria, Australia (w.woodgate@gmail.com) \\ ${ }^{\mathrm{d}}$ European Forestry Institute, Kuala Lumpur, Malaysia (andrew.haywood@efi.int)
}

\section{Commission VIII, WG VIII/7}

KEY WORDS: remote sensing, data primitive, woody attribution, LiDAR, in situ observation, feature extraction.

\begin{abstract}
:
This paper presents a methodology for the attribution and characterisation of Sclerophyll forested landscapes over large areas. First we define a set of woody vegetation data primitives (e.g. canopy cover, leaf area index (LAI), bole density, canopy height), which are then scaled-up using multiple remote sensing data sources to characterise and extract landscape woody vegetation features. The advantage of this approach is that vegetation landscape features can be described from composites of these data primitives. The proposed data primitives act as building blocks for the re-creation of past woody characterisation schemes as well as allowing for recompilation to support present and future policy and management and decision making needs.

Three main research sites were attributed; representative of different sclerophyll woody vegetated systems (Box Iron-bark forest; Mountain Ash forest; Mixed Species foothills forest). High resolution hyperspectral and full waveform LiDAR data was acquired over the three research sites. At the same time, land management agencies (Victorian Department of Environment, Land Water and Planning) and researchers (RMIT, CRC for Spatial Information and CSIRO) conducted fieldwork to collect structural and functional measurements of vegetation, using traditional forest mensuration transects and plots, terrestrial lidar scanning and high temporal resolution in-situ autonomous laser (VegNet) scanners.
\end{abstract}

Results are presented of: 1) inter-comparisons of LAI estimations made using ground based hemispherical photography, LAI 2200 PCA, CI-110 and terrestrial and airborne laser scanners; 2) canopy height and vertical canopy complexity derived from airborne LiDAR validated using ground observations; and, 3) time-series characterisation of land cover features.

1. Accuracy targets for remotely sensed LAI products to match within ground based estimates are \pm 0.5 LAI or a $20 \%$ maximum (CEOS/GCOS) with new aspirational targets of 5\%). In this research we conducted a total of 67 ground-based method-to-method pairwise comparisons across 11 plots in five sites, incorporating the previously mentioned LAI methods. Out of the 67 comparisons, 29 had an RMSE $\geq 0.5$ LAIe. This has important implications for the validation of remotely sensed products since ground based techniques themselves exhibit LAI variations greater than internationally recommended guidelines for satellite product accuracies.

2. Two methods of canopy height derivation are proposed and tested over a large area (4 Million Ha). 99th percentile maximum height achieved a RMSE of $6.6 \%$, whilst 95th percentile dominant height a RMSE $=10.3 \%$. Vertical canopy complexity (i.e. the number of forest layers of strata) was calculated as the local maxima of vegetation density within the LiDAR canopy profile and determined using a cubic spline smoothing of Pgap. This was then validated against in-situ and LiDAR observations of canopy strata with an RMSE 0.39 canopy layers.

3. Preliminary results are presented of landcover characterisation using LandTrendr analysis of Landsat LEDAPS data. kNN is then used to link these features to a dense network of 800 field plots sites.

\section{Background}

State and Commonwealth land management agencies are mandated by the Australian National Forest Policy Statement (1992) to map and report Australian native woody vegetation condition i.e. extent, configuration and health. This is currently achieved at a state level using networks of inventory plots. For example, Victoria has a network of 7860.04 ha permanent inventory plots which are revisited on $\sim 5$ year rotation. These plots are located in state forest and national parks (Department of Environment and Primary Industries, 2013). Utilising the field inventory data in conjunction with Aerial Photo
Interpretation (API) techniques, estimates of forest extent have been produced (Mellor et al., 2012).

More recently, Airborne Light Detection and Ranging (LiDAR) data has been acquired for the assessment of specific local areas, providing accurate estimates of vegetation structure (Stone and Haywood, 2006; Quadros et al., 2011). Such datasets have been used for large-area assessment in combination with synoptic satellite data. However, there remains a lack of standardised, accurate and affordable operational procedures to characterise the woody vegetation at the large area scale. 


\section{Data primitives}

The choice of woody vegetation fundamental descriptors consisted of three steps:

(i) A set of descriptors were selected based on international directives, namely the Committee on Earth Observation Satellites (CEOS) Essential Climate Variables (ECVs) and the indicators selected by the Montreal Process Working Group (Montreal Process Implementation Group for Australia and National Forest Inventory Steering Committee, 2013).

(ii) The set of descriptors were sent to 70 end users from Australian and New Zealand academic, industrial and governmental sectors. Each participant responded a survey ranking the list of indicators according to importance (Axelsson et al., 2012).

(iii) A workshop was held with Australian state and federal agencies prioritise and select from the 99 of the highly ranked descriptors. In this workshop, federal agencies (DAFF and ABARES) and state agency representatives from Victoria, New South Wales and Queensland met to take a decision about the descriptors that were more relevant for their needs. From the end-user survey, tree height, forest condition, canopy fractional cover and the vertical canopy profile were ranked as the most useful forest descriptors.

\section{Study sites}

Within Victoria three $25 \mathrm{~km}^{2}$ sites were chosen (Table 1). These sites were selected as representative of major Victorian forest types. The study sites are also now part of the validation network established by the Auscover facility (www.auscover.org) of the Terrestrial Ecosystem Research Network (TERN) in collaboration with the Victorian Department of Environment, Land, Water and Planning (DELWP). The first site is located in a Box-Ironbark forest in central Victoria $(36.74 \mathrm{~S}, 144.96 \mathrm{E})$ and is dominated by Red Ironbark (Eucalyptus tricarpa), Red Stringybark (Eucalyptus macrorhyncha) and Red box (Eucalyptus polyanthemos) where trees reach a maximum height of 25 metres and the understorey layer is very sparse. The study site is located in the Victorian Midlands Interim Biogeographic Regionalisation for Australia bioregion (IBRA, Australian Department of Sustainability, Environment, Water, Population and Communities). The second site is a wet sclerophyll forest (Southeast Highlands IBRA bioregion) where vegetation cover is dense, predominantly consisting of a tall dominant canopy and shade tolerant strata (37.69S, 145.68E). Species comprise mature stands of Mountain Ash (Eucalyptus regnans), Shining Gum (Eucalyptus nitens) and Alpine Ash (Eucalyptus delegatensis). The third study site is a Dry Sclerophyll forest characterised by high species diversity and is located in South East Corner bioregion (37.48S, 148.33E). The terrain is undulating creating unique vegetation communities, such as shrubby dry forest on the upland slopes, wet forest at higher altitudes and grassy woodland or dry forest in river valleys.

\section{LAI}

Accuracy targets for remotely sensed LAI products to match within ground based estimates are \pm 0.5 LAI or a $20 \%$ maximum (CEOS/GCOS) with new aspirational targets of 5\%). In this research we conducted a total of 67 ground-based method-to-method pairwise comparisons across 11 plots in five sites, incorporating the previously mentioned LAI methods. Out of the 67 comparisons, 29 had an RMSE $\geq 0.5$ LAIe. This has important implications for the validation of remotely sensed products since ground based techniques themselves exhibit LAI variations greater than internationally recommended guidelines for satellite product accuracies.

\section{Canopy height and strata derivation}

A multi-scale remote sensing approach was taken, where plot scale measurements were up-scaled to attribute large areas. Initially, LiDAR derived metrics applicable at the plot scale were tested at the three $5 \mathrm{~km} \mathrm{x} 5 \mathrm{~km}$ study areas -where forests cover a broad range of structural types. Results indicate existing metrics of canopy height were applicable across the range of forest types, for example the 95th percentile of LiDAR derived height estimated inventory measured canopy height with a RMSE of $12 \%(\sim 5 \mathrm{~m})$. An existing mixture modelling technique to attribute the canopy height profile was found unsuitable when applied across heterogeneously forested landscape. This was due to the inability to parameterise the model correctly without a priori knowledge of forest structure e.g. presence or absence of shade tolerant layers. For this reason a new technique was developed utilising a nonparametric regression of LiDAR derived gap probability that generalised the canopy profile. Taking the second derivative of the regression curve identified locations within the canopy that correspond with canopy strata, this therefore allowed a dynamic attribution of canopy vertical structure. Model output was validated with a crown volume modelling approach at 24 plots, where crown models were parameterised with inventory data and allometry. Results indicate this technique can estimate the number of canopy strata with a RMSE of 0.41 strata. Furthermore, the new technique met the transferability criteria, as a universal regression coefficient was transferable between forest types with different structural attributes.

As LiDAR acquisitions that cover large areas will inevitably encounter a range of forest types, parameters for attributing canopy structure that were transferable between forest types were investigated; in particular sampling frequency. To effectively assess a range of pulse densities would require repeat capture over a study area at a range of flying heights, which would be prohibitively expensive. For this reason a new technique was developed that systematically thinned point clouds. This technique differs from previous approaches by allowing simulation of multi-return instruments as well as repeat capture of the same plot. Six sites from around Australia were utilised which covered a broad range of forest types, from open savanna to tropical rainforest. For a suite of metrics, the ability of progressively less dense point clouds ( $4-0.05 \mathrm{pl} \mathrm{m}$ 2) to estimate canopy structure was estimated by comparison with higher density data $(10 \mathrm{pl} \mathrm{m}-2)$. Results indicate that canopy structure can be adequately attributed with data captured at $0.5 \mathrm{pl} \mathrm{m}-2$. When pulse densities are $<0.5 \mathrm{pl} \mathrm{m}-2$, the inability to adequately identify ground resulted in poor metric estimation, this was particularly evident in high biomass forest. Conversely at lower pulse densities in savanna systems, the inability to characterise sparse vegetation resulted in poor attribution of the canopy profile.

Techniques derived at the plot scale were then applied to estimate canopy height across 2.9 million hectares of heterogeneous forest. Canopy height in the study area ranged from $0-70 \mathrm{~m}$ and comprised forest types from open woodland to tall closed canopy rainforest. LiDAR derived canopy height was used to train ensemble regression trees (random forest), where predictor datasets included synoptic passive optical imagery and other ancillary spatial datasets, such as Landsat 
TM and MODIS. Results suggest canopy height can be estimated with a RMSE of $30 \%(5.5 \mathrm{~m})$ when validated with an independent inventory dataset. This is a similar error to that reported in previous studies for less complex forests and is within the European Space Agency target for canopy height estimation. However, model output did show a systematic error, where the height of short and tall forests were over and underestimated respectively. This was corrected by subtracting a modelled estimate of error from the random forest output. Production of a canopy height map over a large area allowed for a consistent product that covered a broad range of forest types, derivation at a $30 \mathrm{~m}$ resolution allowed the identification of landscape features such as logging coupes. The presented technique utilised an open source computing framework as well as freely available predictor datasets to facilitate uptake of by land management agencies and forest scientists.

\section{ACKNOWLEDGEMENTS}

The authors would like to acknowledge the funding institutions: Cooperative Research Centre for Spatial Information (CRCSI), the Victorian Department of Land, Water and Planning (DELWP) and TERN/AusCover.

All new software tools and techniques developed by the CRCSI project 2.07 were written using open source software, this was designed to allow easy adoption by land management agencies (http://www.crcsi.com.au/impact/woody-vegetation/). Python (https://www.python.org/), R (R Development Core Team 2011) and QGIS (QGIS Development Team 2009) were the main packages used.

\section{REFERENCES}

Axelsson, C., Jones, S., Haywood, A., Suarez, L., Wilkes, P., Woodgate, W., Soto-Berelov, M.,Mellor, A. Key attributes for monitoring and assessing Australian forests: a land management perspective. Proceedings of the Geospatial Science Research Symposium GSR2, December 2012, Melbourne. ISBN: 978-0-9872527-1-5.

Department of Environment and Primary Industries, 2013. Ecological Vegetation Classes [WWW Document]. URL http://www.dse.vic.gov.au/conservation-andenvironment/ecological-vegetation-classes-evc (accessed 5.1.14)

Mellor, A., Jones, S. D., Haywood, A., \& Wilkes, P. (2012). Using random forest decision tree classification for large area forest extent mapping with multi-source remote sensing and GIS data. In ARSPC (Vol. 2, pp. 19). Melbourne.

Montreal Process Implementation Group for Australia and National Forest Inventory Steering Committee, 2013, Australia's State of the Forests Report 2013, ABARES, Canberra, December. CC BY 3.0.

National Forest Policy Statement. A new focus for Australian Forests (1992). Australian Government,
Department of Agriculture. Commonwealth of Australia 1992, 1995.

Quadros, N., Frisina, R., \& Wilson, P. (2011). Using Airborne Survey to map Stream Form and Riparian Vegetation Characteristics across Victoria. In Proceedings of SilviLaser 2011 (pp. 1-12). Hobart, Australia.

Stone, C., Haywood, A. (2006). Assessing canopy health of native eucalypt forests. Ecological Management \& Restoration 7 (s1), S24-S30. 
The International Archives of the Photogrammetry, Remote Sensing and Spatial Information Sciences, Volume XLI-B8, 2016 XXIII ISPRS Congress, 12-19 July 2016, Prague, Czech Republic

Table 1. Description of the three study sites

\begin{tabular}{|c|c|c|c|c|c|}
\hline Site & Abbreviation & Description & Dominant forest type* (>10\% of study area) & Canopy height & Annual rainfall $(1981-2010 \mathrm{mean})^{\wedge}$ \\
\hline Mixed species forest & MSF & $\begin{array}{l}\text { Mixed species forest of moderate } \\
\text { height (number of species } \sim 70 \text { ) }\end{array}$ & $\begin{array}{l}\text { Riparian Forest, Damp Forest, Shrubby Dry } \\
\text { Forest }\end{array}$ & $20-50 \mathrm{~m}$ & $833.4 \mathrm{~mm}$ \\
\hline Tall closed forest & TCF & $\begin{array}{l}\text { Very tall, dense, high } \\
\text { productivity forest (Keith et al., } \\
\text { 2009) predominantly consisting } \\
\text { of regrowth from } 1939 \text { fire } \\
\text { except in localised protected } \\
\text { areas where pre-1939 patches of } \\
\text { forest still remain (Lindenmayer } \\
\text { et al., 2000). }\end{array}$ & $\begin{array}{l}\text { Montane Wet Forest, Wet Forest, Riparian } \\
\text { Forest, Cool Temperate Rainforest, Montane } \\
\text { Damp Forest }\end{array}$ & $20-90 \mathrm{~m}$ & $1122.0 \mathrm{~mm}$ \\
\hline
\end{tabular}

Figure 1. Canopy height derived from Landsat and MODIS satellite imagery using ensemble regression tree methods.

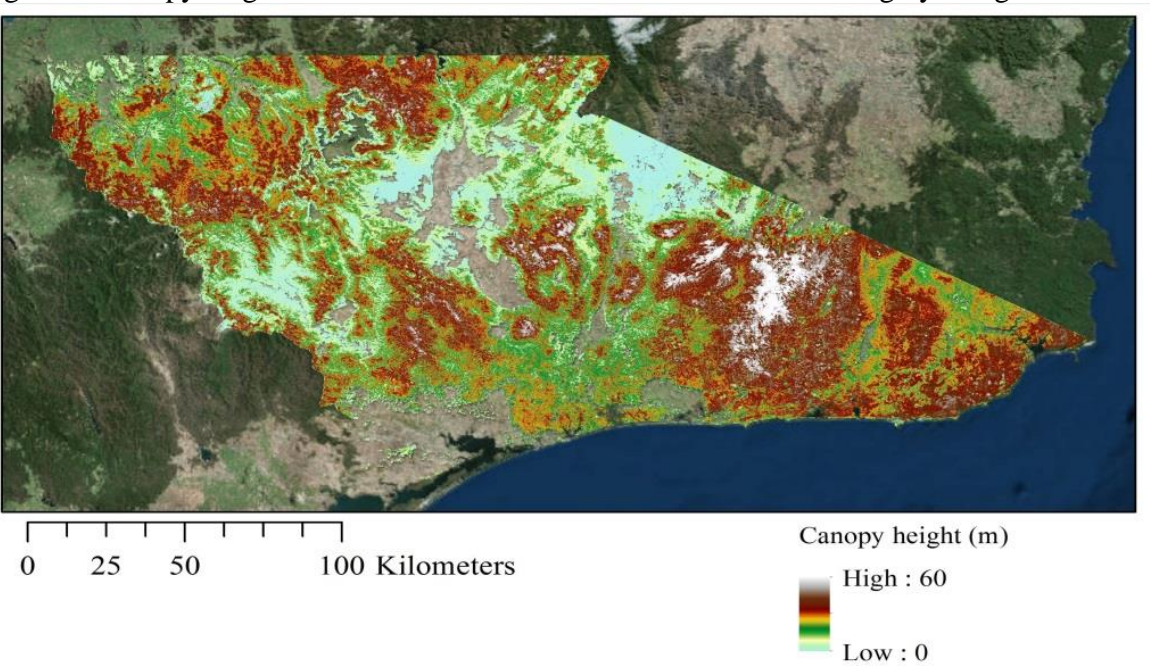

